\title{
A comparative study of adoloscents' perceived stress and health outcomes among adolescent mothers and their infants in Lesotho
}

\author{
EM Yako, PhD \\ Lecturer, Department of Nursing Sciences, University of Fort Hare
}

\section{Keywords:}

Adolescent, Infant, Lesotho, Outcomes, Pregnancy, Stress

\section{Correspondence address:}

Dr Elizabeth Yako

University of Fort Hare

Department of Nursing Sciences

POBox 1054

East London

2501

Tel.: (043) 722-4372

Fax: (043) $722-4391$

E-mail : eyako $@$ ufh.ac.za

\begin{abstract}
Curationis 30(1): 15-25
Purpose

The purpose of this study was to compare perceived stress in general, stress due to pregnancy, and post partum complications between a group of unmarried adolescent first-time mothers and a group of married adolescent first-time mothers. Never-pregnant adolescents served as a comparison group on perceived stress. Health outcomes of infants of the two groups of adolescent mothers were also compared on birth weight, nutritional status (weight gain) and immunization status.
\end{abstract}

\section{Methods}

The study design was non-experimental, comparative and descriptive. A convenience sample of dyads of 64 unmarried adolescent mothers and their infants, 64 married adolescents and their infants, and 64 high school students participated in this study. Data were collected in 3 hospitals, 2 health centres (clinics) and a high school in Lesotho. The differences between the three groups of adolescents in perceived stress, were determined using ANOVA. The t-test was used to determine the differences between the group of unmarried adolescent mothers and the group of married mothers on stress due to pregnancy. The difference in postpartum complications between these two groups of adolescent mothers was determined using Chi-square. The t-test was also used to determine differences in birth weight, nutritional status and immunization status between the group of infants of unmarried mothers and infants of married mothers.

\section{Findings}

Findings of this study revealed significant differences in perceived stress between both groups of adolescent mothers and the group of never pregnant adolescents $(p<$ .0001 ). The Chaffe' test revealed that never pregnant adolescents had lowest levels of perceived stress than both groups of adolescent mothers $(p<.0001)$. Both groups of adolescent mothers had high levels of stress due to pregnancy and the difference between the two groups was non-significant. No differences were observed between infant health outcomes of unmarried mothers and infants of married mothers. The infants of both groups were generally healthy and the majority of them had appropriate type and doses of immunizations six weeks post birth.

\section{Conclusion}

Adolescent mothers in the low lands of Lesotho perceive pregnancy to be a stressful event despite marriage. Therefore adolescents should be discourage from early childbirth. Policy makers need to come up with gender sensitive policies that will make it easier for girls who get pregnant to continue with their education, so that they may be productive and self-reliant. 


\section{Introduction}

Pregnancy is a natural phenomenon that is embraced with joy if it is well planned. Yet, even under ideal conditions, it is a potential stressor. The pregnant mother has to meet her own needs as well as the needs of her unborn infant (Seller, 2003:17(5). Pregnancy among adolescents is even more stressful as the adolescent is not yet ready to take full responsibility for another life. Because in most cases the pregnancy is not planned, it causes a lot of stress on the adolescent (Mngadi, Thembi, RansjoArvidson, \& Ahlberg 2002:38). Her life suddenly changes. She has to cater for her own developmental needs and the needs of her unborn infant (Seller, 2003:1715). Pregnancy is also an indication that such adolescents engaged in unprotected sex. This practice exposes such adolescents to HIV/AIDS with fatal consequences (World Bank, 2004:1).

The families of these adolescents are burdened with the responsibility of supporting the adolescent and her infant physically, mentally and financially. The financial support becomes quite a challenge in the families that are already poor. In some cases the parents of the pregnant adolescents may be very angry with her and not give her the support she needs. In the majority of cases the boyfriend denies the pregnancy for fear of expulsion from school and jeopardizing his future (Motlomelo \& Sebatane (1999: 22).

Traditionally, women in Lesotho as in other A frican counties play a submissive role in a relationship. They do not negotiate the use of condoms and end up with pregnancy, HIV infection and Sexually Transmitted Diseases (STDs) (Moon, Khumalo-Sakutukwa, Heiman, Mbizvo and Padia, 2002:19). Lesotho Planned Parenthood (2005:1) points out that women in Lesotho are considered as minors under both the customary and civil laws thus making it difficult for them to exercise their decision to use contraceptives.

The boyfriends of adolescent girls bully their girlfriends by dictating the terms of sex and often beating these girls. Yet, the latter remain in these abusive relationships for fear of further abuses by their partners (Wood, Maforah and Jewkes, 1998:233; Vundile, Maforah, Jewkes and Jordaan (2001:52). Adolescent pregnancy is only acceptable among married adolescent in Lesotho. Pregnancy among unmarried adolescents carries social stigma (Mturi \& Moerane,
2001:259). These negative factors culminate in stress among the affected adolescents. Yet, very few studies have been done on stress in pregnant and parenting adolescents in Lesotho.

\section{Background}

A number of factors seem to contribute to the high pregnancy rate in Lesotho. The main factors are poor economy, culture and educational system. Lesotho is a poor country heavily dependent on South Africa economically. About forty percent of the male labour force that work as migrant labourers mainly in the mines and quarries in South Africa are being retrenched on an on-going basis (Omole, 2003:2; UNICEF, 2003:1). This has resulted in a high unemployment rate, which is estimated at $45 \%$ (2000 statistics) (World Factbook, 2003:5). Unfortunately these labourers are compelled to return to Lesotho where job opportunities are very limited (Omole, 2003:2). Consequently, they move from their villages to the main cities seeking employment, which is not always available. Although the families of the migrant labourers benefitted economically from the mines and other employing organizations, the migrant labour system also had some drawbacks. This system weakens the family institution. Whether these men are in South Africa or job seeking in the major cities of Lesotho, they are not available to guide their children.

It is contrary to Basotho culture for adults to discuss issues related to sex and sexuality with children. Discussing these issues is perceived as encouraging children to engage in sexual activity prematurely. Consequently, adolescents get information on sex and sexuality from their own friends who also have deficient knowledge of the subject (Yako, 2000: 8). Basotho culture also encourages early marriages. Because parents get Lobola (the bride price) when their daughters marry, they encourage their daughters to marry early in life in order to augment the family income (UNICEF, 2003:1).

Inaccessibility of high school education in terms of cost also contributes to early adolescent pregnancy in Lesotho. Education is accessible to learners at primary school level. The parents of learners pay nominal fees in the primary schools. The government of Lesotho introduced the free primary school education in 2000 beginning with the first graders. This progresses annually so that by 2006 all the seven grades of primary education will be covered (UNICEF, 2003:1). After primary education, a number of adolescents face a problem of continuing with their education. On one hand their parents are too poor to afford school fees in the high schools, and on the other hand, they (the adolescents) are also too young and unskillful to acquire well paying jobs. Some of these adolescents opt for marriage while others engage in sexual relations out of frustration or material gain from older men (Okpani \& Okpani, 2000: 40). While others engage in minimum paying jobs such as baby-sitting or domestic work. Adolescents in this latter group are also at the risk of engaging in sex with older men in order to augment their salaries.

Very few studies have been done on adolescent pregnancy in Lesotho. Therefore, it is not clear what stresses pregnancy brings to the adolescent mother and the impact of the pregnancy on the health of the adolescent and her infant. It is also not clear whether marital status makes any significant difference in the health of this group.

The purpose of this study was to determine the difference in stress among unmarried pregnant adolescents, married pregnant adolescents and single never pregnant adolescents. In addition it sought to determine the difference in post partum complications between the married and married mothers. Health outcomes of infants of the two groups of adolescent mothers were also compared on birth weight, nutritional status (weight gain) and immunization status.

Findings of the study presented in this paper will provide baseline data on psychological and physical health of 15 to 19 year old adolescents, and on the health status of the infants of these adolescents. In addition, it will potentially assist the nurses in planning health promotion programmes and contribute in the development of gender responsive policies for adolescents in Lesotho.

\section{Research questions}

This study attempted to answer the following questions:

1 Is there a difference in stress among unmarried pregnant adolescents, married pregnant adolescent and single never pregnant adolescents?

2 Is there a difference in stress due to pregnancy between married and unmarried adolescent mothers? 
Is there a difference in post partum complications between married and unmarried adolescent mothers? Is there a difference in birth weight, nutritional status (weight gain) and immunization status between the infants of married and unmarried adolescent mothers?

\section{Definition of terms}

Selye (1956: 54) conceptually defines stress as the "state manifested by a specific syndrome, which consists of all the nonspecifically induced changes within a biologic system." In this study stress was viewed from two perspectives 1) general stress, which was operationalised as hassles of daily living and, 2) pregnancy stress which was operationalised as pregnancy concerns. Post partum complications are the complications which the mother might get following delivery. It was operationalised by the Post Partum Checklist.

\section{Methodology \\ Design}

The design study was cross-sectional, comparative and descriptive. Because no studies had been done on the impact of pregnancy on the health of adolescents in Lesotho, an exploratory type of design, which compared two or more samples, was found to be more appropriate in providing more information on perceived stress and health outcomes among the adolescents and their infants (Burns \& Grove, 1993:294).

\section{Sample}

A convenience sample of 64 parenting single adolescents and 64 parenting married adolescents were be selected from thee hospitals and two health centres (clinics) in the Health Service Areas (HSAs) of Maseru, Maluti (3) Leribe and Butha-buthe. A comparison group of 64 non-pregnant adolescents were recruited from a high school in the Mapoteng area. This school mostly served students in the Mapoteng town and the surrounding villages.

Participants had to meet the following criteria to be included in the study: (1) between the ages of 15 and 19 at the time of study, (2) singleton birth, (3) primiparity, (4) attendance of the clinic visit 6 weeks post delivery at the time of study and, (6) ability to read and write Sesotho (local language) or English. Criteria for inclusion of never pregnant adolescents were: (1) not pregnant or parenting at the time of the study, (2) between ages of 15 to 19 years. Criteria for exclusion from the study were: (1) hospitalization with a serious medical or surgical condition and, (2) severe mental disturbance.

Alpha of 0.05 , a power of 0.80 , and a medium effect size of 0.25 were established for estimation of the sample size. Based on the Analysis of Variance (ANOVA and ANCOVA) tables, a sample of 54 adolescents per group were required for this study. However, the principal investigator over sampled by $18 \%$, making the sample 64 adolescents per group in order to make allowance for attrition and missing data (Cohen, 1988).

\section{Setting}

Lesotho is divided into 19 Health Service Areas (HSA). The 18 HSAs are composed of a hospital and the health centers in the surrounding area (CopyWrite, 2000:3). The 19th HSA is made of the Lesotho Flying Doctor Service that serves clinics in the remote mountainous areas (CopyWrite, 2000: 5). Each HSA is responsible for delivery of health care services in the area. The HSA hospital supervises all the health centers in the area irrespective of ownership. Nine HAS hospitals belong to the Christian Health Association of Lesotho (CHAL), and the rest belong to the government (CopyWrite). This study was conducted in the low lands due to accessibility of subjects and costs. Potential subjects were from both the rural areas and the urban areas.

\section{Data Collection}

The principal investigator trained two research assistants in data collection. These assistants were registered nurses and registered midwives that had experience in working in the maternal child health $(\mathrm{MCH})$ clinics. They were introduced to the different instruments and shown how to fill out these instruments. To test for inter-rater reliability, the principal investigator and the two research assistants interviewed 10 adolescents simultaneously, and completed questionnaires, reviewed 10 health booklets for variables of interest and completed relevant checklists. The principal investigator's codings and codings of each of the research assistants were compared for agreements and disagreements. Topf (1986:254) indicates that there is consensus among behavioral scientists that an average agreement of " $70 \%$ is necessary, $80 \%$ is adequate, and $90 \%$, is good". There was $100 \%$ agreement between the principal investigator and the research assistants. Data were collected six weeks post delivery at a routine postnatal clinic. This was done immediately following full explanation of the study and signing of the consent form by the adolescents and by the mothers of those under age. Questionnaires were distributed before assessment of the adolescents during the postnatal visits. The research team guided the adolescents by answering their questions and making any clarifications on the questionnaires. Data on maternal outcomes and infant outcomes were obtained from patients' health booklets ("Bukana" in Sesotho; the local language) and from hospital records.

The principal, teachers, and students in the high school were given the same explanation of the study as pregnant adolescents. A letter explaining the study and a consent form was given to each of the potential participants to give to her parent. Each of these parents and the student were requested to sign the consent form. Data were collected three days later after school within the same time frame as parenting adolescents.

\section{Protection of Human Subjects}

The study was carried following the guidelines of the Case Western Reserve University Institutional Review Board and the (Lesotho) Ministry of Health and Social Welfare research ethics committee. Participants' rights of confidentiality and anonymity were respected and they were given the freedom to withdraw from the study at any point.

\section{Instruments}

The instruments that were used to measure data in this study are summarized in Table 1. These instruments were selected based on their reliability and validity, and use across cultures, especially, their applicability in an African context. The principal investigator translated the instruments into Sesotho and tested the instruments for accuracy of the translation. These instruments were given to two people who were fluent in both languages to translate back into the English version. The group then checked if the meaning remained unchanged. The procedure was repeated 


\begin{tabular}{|c|c|c|c|c|}
\hline Concept & Measurement & $\begin{array}{l}\text { Level of measurement } \\
\text { \& Possible Scores }\end{array}$ & $\begin{array}{l}\text { Cronbach's Alpha } \\
\text { From the Literature }\end{array}$ & $\begin{array}{l}\text { Cronbach's Alpha } \\
\text { From Study Sample }\end{array}$ \\
\hline \multirow[t]{2}{*}{ Stress } & $\begin{array}{l}\text { (1) Daily Hassles } \\
\text { 53-ltem Scale } \\
\text { Developed by Kanner, } \\
\text { Coyne \& Lazarus ( } 1981 \text { ) } \\
\text { Revised by Delongis, } \\
\text { Coyne Folkman \& } \\
\text { Lazanus (1988) }\end{array}$ & $\begin{array}{l}\text { Ordinal scale } \\
\text { Likert scale 0-3) }\end{array}$ & 0.97 & 0.89 \\
\hline & $\begin{array}{l}\text { (2) Feeling of Pregnancy } \\
\text { Questionnaire (FOPQ) } \\
\text { 78-Item Scale (For Women) } \\
\text { Developed by Glazer ( } 1979 \text { ) } \\
\text { Modified by Glazer (1984) }\end{array}$ & $\begin{array}{l}\text { Ordinal scale } \\
\text { (Likert scale 0-3) }\end{array}$ & 0.96 & 0.88 \\
\hline \multicolumn{5}{|c|}{ Others Developed by the researcher } \\
\hline $\begin{array}{l}\text { Postpartum } \\
\text { Complications }\end{array}$ & \begin{tabular}{|l|} 
(3) Postpartuin \\
Complication \\
Checklist \\
12-Item Checklist
\end{tabular} & Nominal scale & $\mathrm{N}^{*}$ & 0.69 \\
\hline Infant Outcomes & (4) Infant Form & Interval scale & $N / A^{*}$ & $N / A^{*}$ \\
\hline $\begin{array}{l}\text { Demographic } \\
\text { Information }\end{array}$ & $\begin{array}{l}\text { (5) Personal Information } \\
\text { Profile }\end{array}$ & & $N / A^{*}$ & $\mathrm{~N} / \mathrm{A}^{*}$ \\
\hline
\end{tabular}

$*=$ Test-retest reliability

$\mathrm{N}^{*}=$ New instrument, reliability not checked

$\mathrm{N} / \mathrm{A}^{*}=$ Not Applicable

until there was $100 \%$ agreement on the meaning of the translations. The instruments were available in both English and Sesotho, and each participant chose a version that she found most comfortable. The instruments were pilot-tested among adolescents. If there was any wording that seemed difficult for the adolescents to understand. a synonym that seemed easy to understand was also provided

In this study stress was measured using the Daily Hassles Scale (DHS. SS), and the Feeling of Pregnancy Questionnaire (FOPQ). The Daily Hassles Scale assesses the frequency and intensity of hassles in a number of areas that include finance and relationship with family members. The time frame was modified from the past one month in the original scale to the past 6 months in order to cover the pregnancy period. The FOPQ measures concerns specifically related to pregnancy and delivery. The postpartum Complication Checklist was used to measure postpartum complications.
Infant outcomes were assessed with the Infant Form. The SPSS 9.0 for windows statistical program was used to measure the internal consistency of the instruments. Reliability of these instruments was computed using the Cronbach's alpha. These instruments are presented in table 1 .

\section{Data Analysis}

The analyses of data were performed using SPSS 9.0 software for windows.

The difference in perceived stress among three groups of adolescents was determined using ANOVA. For this analysis, perceived stress was viewed as the dependent variable.

The difference in perceived stress (due to pregnancy) between the two groups of adolescents was determined using a ttest for independent samples. The differences in postpartum complications between these two groups of adolescent mothers were determined using Chisquare. A t-test for independent samples was used to determine the differences in birth weight, nutritional status and immunization status between the two groups of infants.

\section{Results \\ Description of the Adolescent Sample}

The sample consisted of 192 adolescent. The adolescent groups were composed of 64 unmarried parenting mothers, 64 married parenting mothers and 64 never pregnant adolescents. The three groups of adolescents did not differ significantly in most characteristics. Unmarried adolescent mothers ranged in age from 15 to 19 years. with the mean of 18.4 years $(\mathrm{S} \mathrm{D}=.93)$. Married adolescent mothers were of similar age, with the mean of 18.8 years, $(S D=.62)$ and a range of ages being 16 to 19 years. Unmarried adolescents were 1 year younger than the two groups of adolescent mothers. Their ages ranged from 16 to 19 years, with the mean of 17.6 years, ( $\mathrm{S} D=.93$ ) $[(F(2,189)=32.33 p<001)]$. The group of never-pregnant adolescents was also more educated than parenting 
Table 2 Demographic characteristics of unmarried adolescent mothers $(n=64)$ married adolescent mothers $(n=64)$ and never pregnant adolescents $(n=64)$

\begin{tabular}{|c|c|c|c|c|c|c|}
\hline Variable & $\begin{array}{l}\text { Unmarried } \\
\text { Number }\end{array}$ & $\%$ & $\begin{array}{l}\text { Married } \\
\text { Number }\end{array}$ & $\%$ & $\begin{array}{c}\text { Never Preg.* } \\
\text { Number }\end{array}$ & $\begin{array}{l}\text { Adol. } \\
\%\end{array}$ \\
\hline $\begin{array}{l}\text { Race } \\
\text { Mosotho } \\
\text { Xhosa }\end{array}$ & 64 & 100 & 64 & 100 & $\begin{array}{c}63 \\
1\end{array}$ & $\begin{array}{c}98.4 \\
1.6\end{array}$ \\
\hline $\begin{array}{l}\text { Education } \\
7 \text { yrs. \& below } \\
\text { J.C* } 1 \text { ( } 8 \text { yrs }) \\
\text { J. C.*2 }(9 \text { yrs }) \\
\text { J. C.*3 } 3(10 \text { yrs }) \\
\text { Matric*.1 (11 yrs) } \\
\text { COSC* (12 yrs.) } \\
\text { College }\end{array}$ & $\begin{array}{c}24 \\
6 \\
15 \\
7 \\
2 \\
8 \\
2\end{array}$ & $\begin{array}{c}37.5 \\
9.4 \\
23.4 \\
10.9 \\
3.1 \\
12.5 \\
3.1\end{array}$ & $\begin{array}{c}23 \\
4 \\
17 \\
11 \\
5 \\
4 \\
0\end{array}$ & $\begin{array}{c}35.9 \\
6.3 \\
26.6 \\
17.2 \\
7.8 \\
6.3 \\
0\end{array}$ & $\begin{array}{c}0 \\
0 \\
0 \\
0 \\
64 \\
0 \\
0\end{array}$ & $\begin{array}{c}0 \\
0 \\
0 \\
0 \\
100 \\
0 \\
0\end{array}$ \\
\hline $\begin{array}{l}\text { Source of fin. } \\
\text { Sup.* } \\
\text { Self } \\
\text { Parents } \\
\text { Husband } \\
\text { Other }\end{array}$ & $\begin{array}{c}8 \\
51 \\
2 \\
3\end{array}$ & $\begin{array}{c}12.5 \\
79.7 \\
3.1 \\
4.7\end{array}$ & $\begin{array}{c}3 \\
10 \\
50 \\
1\end{array}$ & $\begin{array}{c}4.7 \\
15.6 \\
78.1 \\
1.6\end{array}$ & $\begin{array}{c}0 \\
64 \\
0 \\
0\end{array}$ & $\begin{array}{c}0 \\
100 \\
0 \\
0\end{array}$ \\
\hline 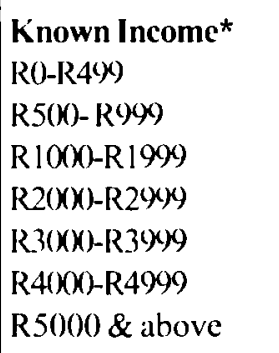 & $\begin{array}{l}16 \\
10 \\
4 \\
2 \\
1 \\
0 \\
0\end{array}$ & $\begin{array}{c}48.5 \\
30.3 \\
12.1 \\
6.1 \\
30 \\
0 \\
0\end{array}$ & $\begin{array}{l}15 \\
16 \\
17 \\
1 \\
1 \\
1 \\
0\end{array}$ & $\begin{array}{c}29.4 \\
31.4 \\
33.3 \\
2.0 \\
2.01 \\
2.0 \\
0\end{array}$ & $\begin{array}{l}2 \\
2 \\
1 \\
1 \\
1 \\
1 \\
1\end{array}$ & $\begin{array}{c}25 \\
25 \\
12.5 \\
12.5 \\
12.5 \\
12.5 \\
12.5\end{array}$ \\
\hline $\begin{array}{l}\text { Employment } \\
\text { Student } \\
\text { Employed } \\
\text { Unemployed }\end{array}$ & $\begin{array}{c}10 \\
7 \\
47\end{array}$ & $\begin{array}{l}15.6 \\
10.9 \\
73.4\end{array}$ & $\begin{array}{l}11 \\
10 \\
43\end{array}$ & $\begin{array}{l}17.2 \\
15.6 \\
67.2\end{array}$ & $\begin{array}{c}64 \\
0 \\
0\end{array}$ & $\begin{array}{c}100 \\
0 \\
0\end{array}$ \\
\hline $\begin{array}{l}\text { Religion } \\
\text { Catholic } \\
\text { Anglican } \\
\text { LEC* } \\
\text { SDA* } \\
\text { Methodist } \\
\text { Other }\end{array}$ & $\begin{array}{c}37 \\
6 \\
10 \\
1 \\
2 \\
8\end{array}$ & $\begin{array}{c}57.8 \\
9.4 \\
15.6 \\
1.6 \\
3.1 \\
12.5\end{array}$ & $\begin{array}{c}30 \\
4 \\
16 \\
2 \\
1 \\
11\end{array}$ & $\begin{array}{c}46.9 \\
6.3 \\
25.0 \\
3.1 \\
1.6 \\
17.2\end{array}$ & $\begin{array}{l}52 \\
0 \\
6 \\
2 \\
0 \\
4\end{array}$ & $\begin{array}{c}8 \\
0 \\
9.4 \\
3.1 \\
0 \\
6.3\end{array}$ \\
\hline
\end{tabular}

Preg. ${ }^{*}=$ Pregnant

J. C ${ }^{*}=$ Junior Certificate

Matric ${ }^{*}=$ Matriculation

$\operatorname{COSC}^{*}=$ Cambridge Overseas School Certificate

Fin. Sup. ${ }^{*}=$ financial support

Income ${ }^{*}=\%$ is based on the numbers of those who knew their parents' income.

LEC $^{*}=$ Lesotho Evangelical Church

$\mathrm{SDA}^{*}=$ Seventh Day Adventist Church

adolescents. The majority $(\mathrm{N}=24) 37.5 \%$, of unmarried adolescent mothers and the majority, $(\mathrm{N}=23) 35.9 \%$, of married adolescent mothers had seven years of schooling or less. Every adolescent girl in this group was in the $11^{\text {th }}$ grade. The difference in education was the result of attempting to match the ages of single never-pregnant adolescents with those of parenting adolescents. Every adolescent in the study was a Mosotho, except one never-pregnant adolescent who reported to be Xhosa. Most, $(\mathrm{N}=$ 33) $51.6 \%$, of married adolescent mothers reported to be living with their husbands. 
Table 4 Descriptive Statistics for Perceived Stress Among Unmarried Adolescent Mothers $(N=64)$ Married Adolescent Mothers $(N=64)$ Never pregnant Adolescents $(N=64)$

\begin{tabular}{|c|c|c|c|c|c|c|}
\hline Variable & Mean & $\begin{array}{l}\text { Irried } \\
\text { SD }\end{array}$ & Mean & $\begin{array}{r}\text { ried } \\
\text { SD }\end{array}$ & $\begin{array}{l}\text { Never pregnant } \\
\text { Mean }\end{array}$ & $\begin{array}{l}\text { Adolescents } \\
\text { SD }\end{array}$ \\
\hline $\begin{array}{l}\text { Perceived } \\
\text { Stress } \\
\text { Daily Hassles } \\
\text { Feeling of } \\
\text { Preg*. } \\
\text { Baby } \\
\text { Self } \\
\text { Health }\end{array}$ & $\begin{array}{l}75.4 \\
130.77 \\
\\
25.12 \\
30.47 \\
18.25\end{array}$ & $\begin{array}{l}25.50 \\
31.26 \\
\\
8.10 \\
8.50 \\
4.93\end{array}$ & $\begin{array}{l}71.40 \\
128.64 \\
\\
25.40 \\
28.03 \\
17.01\end{array}$ & $\begin{array}{l}22.65 \\
29.68 \\
\\
6.83 \\
8.30 \\
5.58\end{array}$ & $\begin{array}{l}53.48 \\
\text { N/A* } \\
\\
\text { N/A* } \\
\text { N/A* } \\
\text { N/A* }\end{array}$ & $\begin{array}{l}23.41 \\
\text { N/A* } \\
\text { N/A* } \\
\text { N/A* } \\
\text { N/A* }\end{array}$ \\
\hline
\end{tabular}

Adol $^{*}=$ Adolescent

Feeling of Preg* = Feeling of Pregnancy

N/A* $=$ Not Applicable

Table 5 Descriptive Statistics of Birth weight, nutritional status and immun. Status ${ }^{\star}$ of Infants of Unmarried Adol. ${ }^{\star}$ Mothers $(N=64)$ Infants of Married Adol. ${ }^{*}$ Mothers $(N=64)$

\begin{tabular}{|l|l|l|l|l|}
\hline \multirow{2}{*}{ Variable } & \multicolumn{2}{|l|}{$\begin{array}{l}\text { Infants of Unmarred Adol.* Mothers } \\
\text { Mean }\end{array}$} & SD & \multicolumn{2}{l|}{ Infants of Married Adol.* Mothers } \\
\hline Birth weight & 2931.88 & 17.6 & 3089.69 \\
Nutritional status & 1663.43 & 593.4 & 1794.69 & 517.63 \\
Immun. Status* & 4.90 & 0.30 & 4.92 & 571.2 \\
& & & 0.51 \\
\hline
\end{tabular}

Adol.* = Adolescent

Immun. Status* $=$ Immunization status

Table 6 A Summary of Analysis of Variance on Daily Hassles scale, for Unmarried Adolescent Mothers $(\mathbf{N}=$ 64), Married Adolescent Mothers ( $N=64$ ) and Never pregnant Adolescents ( $N=64$ )

\begin{tabular}{|l|l|l|l|l|l|l|}
\hline Scale & Source & SS & DF & MS & F & Sign*.of F \\
\hline DHS* & Between Groups & 17480.2 & 2 & 8740.1 & 15.3 & $0001^{* *}$ \\
& Within Groups & 107855.2 & 189 & 570.7 & & \\
& Total & 125335.4 & 191 & & & \\
\hline
\end{tabular}

$* * \mathrm{P}<0001$

DHS* = Daily Hassles Scale, Sign*=Significance

Infants of unmarried mothers were born by normal vaginal delivery, Cesarean section and forceps delivery, $(\mathrm{N}=60$, $93.8 \%, \mathrm{~N}=3,4.7 \%$ and $\mathrm{N}=1) 1.6 \%$ respectively). Sixty $(93.9 \%)$ infants of married mothers were born by normal vaginal delivery, $3(4.7 \%)$ by Cesarean section, and $1(1.6 \%)$ by vacuum extraction.
Apgar scores for the two groups of infants were similar at 1 minute and five minutes post birth. The mean Apgar score for infants of unmarried mothers was 8.3, $(\mathrm{SD}=1.9)$ at birth and 9.6, $(\mathrm{SD}=$ $1.0)$ at 1 minute and 5 minutes respectively post birth. Infants of married mothers' mean score was, 8.8, $(\mathrm{S} \mathrm{D}=1.08)$, and $9.96,(\mathrm{SD}=.21)$ at 1 minute and 5 minutes respectively.

The majority of infants in both groups were breast-fed. Thirty-four $(53.1 \%)$ infants of unmarried mothers received breast feeding only, $29(45.3 \%)$ bottle fed only, and (1.6\%) both bottle and breast-fed. Thirty-nine $(60.9 \%)$ infants of married adolescent women were breast fed, 23 (35\%) were bottle fed, and 2 (3. I 
Table 3 Descriptive statistics: Infants of unmarried adolescent mothers $(n=64)$ and infants of married adolescent mothers $(\mathrm{N}=64)$

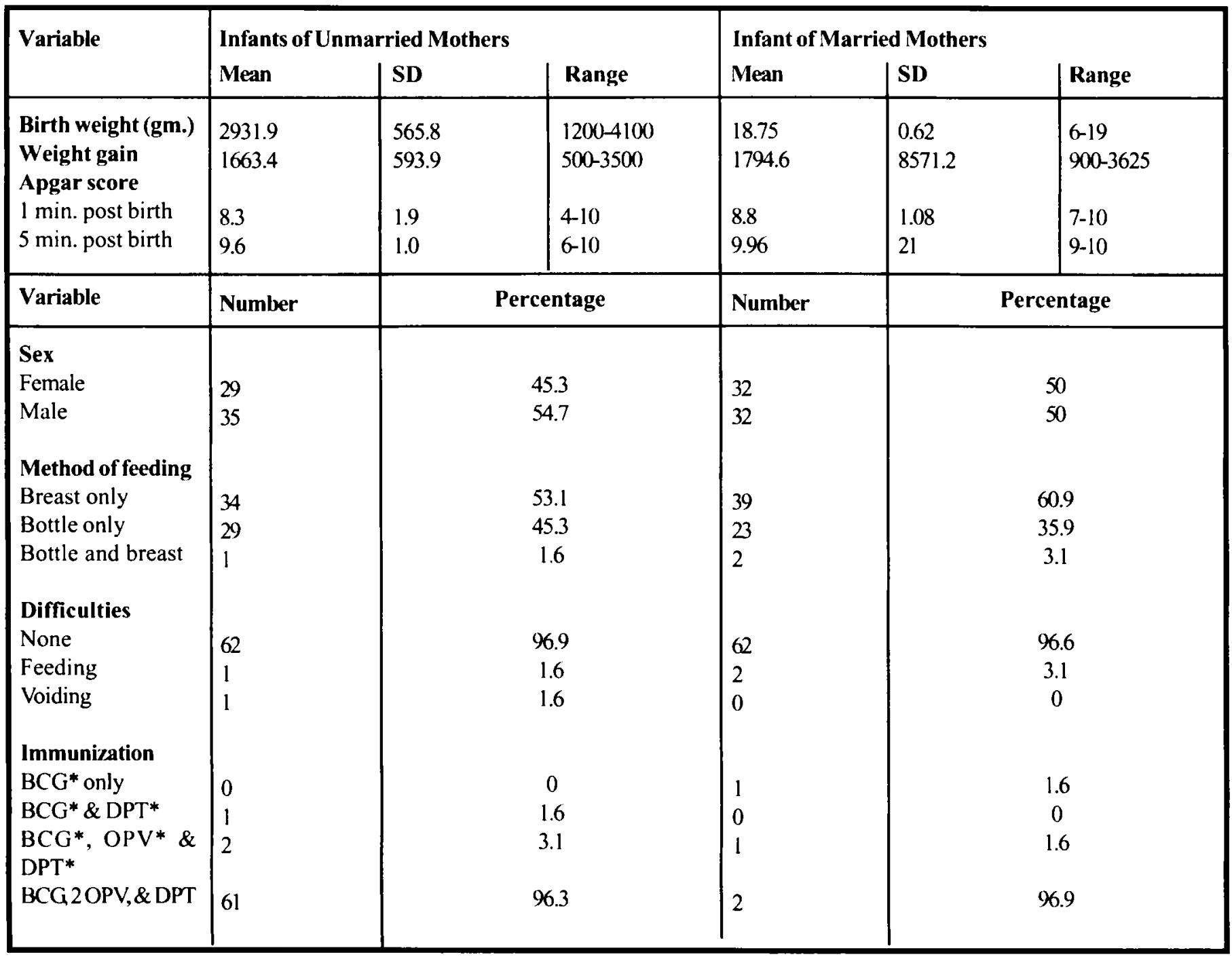

BCG $^{*}=$ Bacille Calmitte-Guerin (Tuberculosis Vaccine)

DPT $^{*}=$ Diphtheria, Polio \& Tetanus

$\mathrm{OPV}^{*}=$ Oral Polio Vaccine

The majority $(\mathrm{N}=38) 59.4 \%$, of unmarried mothers lived with their own mothers and the majority, $(\mathrm{N}=45) 70.2 \%$, of neverpregnant adolescents lived with both parents. The majority of both unmarried and married adolescent mothers were unemployed, $(\mathrm{N}=4773 \%$ and $\mathrm{N}=43$ $67.2 \%$ respectively). All participants in the comparison group were high school students. Most, $(\mathrm{N}=50) 78.1 \%$, married adolescent mothers reported their husbands as their main source of financial support. Most, ( $N=51) 79.7 \%$, unmarried adolescent mothers and all never pregnant adolescents were supported by their parents. Both groups of mothers came from low-income families. Some adolescent mothers did not know their supporter's income. However, of those who had information on their supporter's income, $(N=31)$
$60.8 \%$ of unmarried mothers and $(\mathrm{N}=26)$ $78.8 \%$ of married mothers reported an income of less than R 1000 per month. The median income of both groups of adolescent mothers was R500 to R999. When asked how well this income met their needs, most unmarried and married mothers felt this income supported their needs poorly, $\mathrm{N}=26,40.6 \%$ and $\mathrm{N}=27$, $42.2 \%$ respectively). The majority, $(\mathrm{N}=$ 52) $87.5 \%$, of single girls did not know their parents' incomes. However most ( $N=34,53.1 \%$ ) of this group felt that their parents' income met their needs very well. Every adolescent in this study reported to be a Christian. The characteristics of the groups of adolescents are presented in Table 2.

\section{Description of the Infant Sample}

One hundred twenty eight infants of adolescent mothers participated in this study. Sixty-four infants belonged to unmarried adolescent mothers and 64 to married adolescent mothers. There were more males than females in the group of infants of unmarried mothers, $(\mathrm{N}=35$, $54.7 \%$ and, $\mathrm{N}=29,45.3 \%$ respectively). Fifty percent of the infants of married adolescent women were female. The mean birth weight of infants of unmarried mothers was 2931.9 grams ( $\mathrm{SD}=565.58$ ), and ranged 1200 to 4100 grams. The mean birth weight of infants of married mothers was 3089.7 grams ( $\mathrm{SD}=517.6)$, and ranged 1700 to 4300 grams. The mean weight gain 6 weeks post birth for infants of unmarried mothers was 1663.4 grams $(\mathrm{SD}=593.9)$, and 1794.7 grams $(\mathrm{SD}=$ 571.2) for infants of married adolescent mothers. The modes of delivery of infants in both groups were similar. 
Table 7 A Summary of Chi-Square analysis on Postpartum Complication Checklist for Unmarried Adolescent Mothers $(N=64)$ and Married Adolescent Mothers ( $N=64)$

\begin{tabular}{|l|l|l|l|}
\hline Variables & $\div$ & DF & Significance \\
\hline Engorged Breasts & 6.30 & 1 & $.01^{*}$ \\
Cracked Nipples & 4.13 & 1 & $.04^{*}$ \\
$\begin{array}{l}\text { Postpartum Hemorrhage } \\
>500 \mathrm{ml}\end{array}$ & 2.80 & 1 & .09 \\
$\begin{array}{l}\text { Hypertension Systolic BP }> \\
140 \mathrm{~mm} \text { HG }\end{array}$ & 2.03 & 1 & .15 \\
$\begin{array}{l}\text { Infected Episiotomy/ } \\
\text { Perenial Tear } \\
\text { Urinary Retention }\end{array}$ & .01 & 1 & .32 \\
\hline
\end{tabular}

$* \mathrm{P}<05$

$\%)$ were both bottle and breast-fed. Characteristics of the infant sample are presented on Table 3.

\section{Descriptions and analyses of perceived stress}

Perceived stress was measured from two perspectives, hassles of daily living and concerns of pregnancy and delivery. Daily hassles were measured using the Daily Hassles Scale. Higher scores on this scale indicated higher levels of hassles. Unmarried parenting mothers had the highest levels of perceived stress ( Mean $=75.44, \mathrm{SD}=25.51$ ), followed by parenting married mothers, (Mean = $71.41, \mathrm{SD}=22.65$ ), and single neverpregnant adolescents $($ Mean $=66.78, \mathrm{SD}$ =25.2).

A one-way ANOVA test of the means of three study groups was done to determine the difference in perceived stress as measured by the Daily Hassles Scale. ANOVA indicated significant differences in daily hassles among the three groups of adolescents $(F(2,189)=$ 15.32, P<.0001). A Post Hoc test (Scheffe' test) was done to determine the differences in means among the three groups (Burns \& Grove, 1993:515). Significant group differences were found between the never-pregnant adolescents and the two groups of adolescent mothers, with the never-pregnant adolescents having lowest perceived stress. The mean difference between the never-pregnant adolescents and unmarried adolescents was -21.95 , $(\mathrm{p}<$
.0001 ), and between the never pregnant adolescent and married adolescents was $-17.92,(p<.000)$. The mean difference between unmarried and married adolescent mothers was small and nonsignificant $(-4.0, p<.64)$.

The feeling of Pregnancy Questionnaire was used to measure pregnancy stress. Higher scores on this measure indicated higher levels of stress. Unmarried adolescent mothers had higher stress levels with a mean of $30.76,(\mathrm{SD}=31.27)$. Married parenting adolescent mothers had a mean of 128.64, $(S D=29.68)$. However, no significant between group differences in stress levels were found. Perceived stress due to pregnancy was measured using FOPQ. A t-test was done to determine the difference in means of the FOPQ scores between the unmarried and married adolescent mothers. The differences in mean scores between these two groups were not significant. Nonsignificant results in maternal concerns were found. Subscales of the FOPQ were assessed to determine major sources of stress among adolescent mothers. Both groups of mothers were concerned more about themselves than the baby.

Scores for the unmarried mothers and the married mothers on the FOPQ subscale concern for self were: mean $=30.47(\mathrm{SD}=$ $8.50)$ and mean $=28.03(\mathrm{SD}=8.30)$ respectively, and on the FOPQ subscale concern for the baby were: mean $=25.12$, $(\mathrm{SD}=8.10)$ and mean $=25.40(\mathrm{SD}=6.83)$ respectively. Non-significant differences between the unmarried and married adolescent mothers were found on pregnancy concerns

$[\mathrm{t}(1.92)=-.394, \mathrm{p}<0.75]$ on the FOPQ total scale. Similar results were found on all the subscales the FOPQ. These analyses indicate that pregnancy and parenting are stressful for the adolescent mothers irrespective of marital status.

In this study, postpartum complications were measured using the Postpartum Complication Checklist. The two groups of adolescent mothers in this sample had few complications. Only 1(1.6\%) married adolescent mother had 1 postpartum complication which was postpartum hemorrhage. Approximately 19 (29.7\%) unmarried mothers had postpartum complications; engorged breasts $(\mathrm{N}=6$, $9.3 \%)$, cracked nipples $(\mathrm{N}=4,6.3 \%)$, postpartum hemorrhage $(\mathrm{N}=5,97.8 \%)$, high blood pressure with systolic pressures of more than $140 \mathrm{~mm} \mathrm{Hg}(\mathrm{N}=$ $2,3.1 \%)$, infected episiotomy $(\mathrm{N}=1$, $1.6 \%)$, and urinary retention $(\mathrm{N}=1,1.6 \%)$. Chi-square analysis was used to determine differences in postpartum complications between unmarried and married adolescent mothers. Chi-square revealed significant difference in engorged breasts between unmarried adolescent mothers and married adolescent mothers [ $c^{2}$ (3.84) 6.30, $p<$ $.01]$. A significant difference in cracked nipples was also found between unmarried and married adolescent mothers, $\left[c^{2}(3.84)=4.12, p<.04\right]$. Non significant results were found in postpartum hemorrhage, hypertension with systolic blood pressure of more than $140 \mathrm{~mm} \mathrm{Hg}$ and diastolic pressure of more than $90 \mathrm{~mm} \mathrm{Hg}$, infected episiotomy and urinary retention. None of the adolescent mothers responded to the rest of the eight items on the scale. The results are presented on Table 7 .

Birth weight of infants in this sample was measure in grams (gm.). The mean birth weight for infants of unmarried adolescent mothers was $2931.88 \mathrm{gm}$. (SD $=565.84)$, and for infants of married adolescent mothers birth weight was $3089.69 \mathrm{gm}$. ( $\mathrm{SD}=517.63)$. Nutritional status was determined by weight gain within the six-week period post birth. Mean weight gain for infants of married mothers was $1794 \mathrm{gm}$ (SD = 571.23), and for infants of unmarried mothers it was $1663 \mathrm{gm}$. $(\mathrm{SD}=593.94)$. Immunization status of infants was determined by observing the number of immunization each infant had. The mean number of 
immunizations infants of unmarried mothers, and infants of married mothers had was $4.90(\mathrm{SD}=.30)$ and $4.92(\mathrm{SD}=$ $.51)$ respectively.

T-tests were used to determine differences in birth weight, nutritional status (weight gain) and immunization status between infants of unmarried adolescent mothers and infants of married mothers. No significant results in birth weight $[\mathrm{t}(1.96)=1.65, \mathrm{p}<.12]$, nutritional status $[\mathrm{t}(1.96)=1.27, \mathrm{p}<.21]$, and in immunization status of infants $[\mathrm{t}(1.96)=$ $.21, \mathrm{p}<.83$ ] were found between infants of unmarried mothers and infants of married mothers. Because t-tests in this study were not significant at alpha 0.05 , Bonferroni's adjustment was not done (Burns \& Grove, 1993:515).

\section{Discussions}

The importance of the findings of this study lies in the provision of information on the impact of pregnancy on the health of adolescent mothers and their infants in the lowlands of Lesotho. Nurses, policy makers, community leaders, and other professionals need to work collaboratively in providing comprehensive health programmes exclusively for adolescents and their infants. Appropriate programmes can only be provided if the needs of the groups have been established. This study provides the baseline information that is needed in the provision of such programmes.

\section{Perceived Stress}

The two groups of mothers had significantly higher stress levels than never-pregnant adolescents. Because this was the first study on perceived stress among adolescent mothers in Lesotho, no determination on the relationships among variables can be proposed.

Both groups of unmarried adolescent mothers and married adolescent mothers obtained high scores on the FOPQ, with non-significant differences between the two groups. Perhaps age and culture influenced the higher stress levels in this study. Adolescent mothers may be finding it difficult to cope with the demands of growing up, and having to deal with the pregnancy and parenting simultaneously. High stress levels among married adolescent mothers were unexpected, since pregnancy in married adolescents is culturally accepted. Perhaps demands of extended families outweigh the help that the mothers get from relatives and friends.

\section{Maternal and Infant Health Outcomes}

Adolescent mothers and infants that participated in this study were generally healthy. Only a few mothers had postpartum complications. It is noteworthy that adolescent mothers had more complications involving the breasts and the nipples. The mother has to take an active role in the prevention for these two complications. Even before the infant is born, the mother has to take care of the breasts and ensure that the nipples are soft and supple. But since adolescent mothers tend to attend fewer antenatal clinic visits than older women (Amini, Catalano, Dieker \& Mann, 1996: 668), adolescent mothers in this study may have had a few or no lessons on breast care.

The infants of both unmarried and married mothers were generally healthy. Both groups of infants were of appropriate weight for gestational age at birth. No significant differences in terms of birth weight and nutritional status were found between the two groups of infants. The findings of the study support the findings of earlier investigators who observed that older adolescent mothers have better matemal and infant health outcomes than younger adolescent mothers do. Therefore, indicating the need to separate these two groups when determining health outcomes (Amini et al., 1996:668; Naeye, 1981:32

No significant differences were found in immunization status between the infants of unmarried and infants of married mothers. The majority of infants had the expected number of doses and types of immunizations at 6 weeks post birth. One limitation of this study is that immunization status was observed at 6 weeks post birth only. In order to contribute meaningful results, infants' immunization status needs to be observed over a long period of time. More longitudinal studies need to be done in this area in Lesotho.

\section{Implications for Nursing Practice}

Nurses are in an ideal position to reduce, stress, among pregnant and parenting adolescent, since nurses have more contact with these groups than any other health professionals. Nurses can potentially help these adolescents in a variety of ways. They need to find out the causes of these high stress levels among these groups, and help these adolescents to find solutions to their problems. Because pregnancy among unmarried adolescents has social stigma, nurses can potentially reduce some of the stress, by organizing the maternal child health services, so that adolescents have comprehensive health care programmes exclusively for adolescents and their infants. The adolescents may feel more comfortable in discussing their problem with their own colleagues, rather than discussing these problems in the presence of older women.

Nurses need to educate adolescent mothers and mothers to be about selfcare, including breast care. With the pandemic of HIV/AIDS and a number of mothers deciding not to breast feed in order to prevent mother transmission of the virus, more mothers will need assistance with breast care. Breastfeeding in public is culturally acceptable in Lesotho and in most African countries, and women generally practice this. However, it may be too embarrassing for the adolescent mother, who may not want the public to know that she has a baby. For this reason, those that choose to breast feed should be supported.

The infants of both groups of mothers had very few health problems, and the majority of infants had the appropriate type and number of doses of immunizations. Considering that immunizations are free in Lesotho, nurses should encourage every mother to take her infant to the clinic for immunization at the appropriate times, following the immunization schedule in the infant's health booklet (Bukana).

\section{Implications for Research}

This study provides baseline information on perceived stress, and health outcomes of the mother and her infant. Further research is needed in this area to determine relationships among the variables. In addition, studies using qualitative methods should be done in order to determine the reasons for breast problems among unmarried adolescent mothers, and also to determine the difficulties these mothers my be facing due to pregnancy and parenting.

Longitudinal studies should be done in order to produce meaning information on immunization and infant nutrition. Over a longer period of time, the mother would have had more discretion of whether to bring her infant to the health center for immunization or not. The infant would have been weaned from the breast, thus exposing the infant to more chances of 
malnutrition, depending on the mother's knowledge and financial situation. Based on this information, nurses will potentially plan and implement effective programs for infants of adolescent mothers. The Ministry of Health in Lesotho needs to allocate more funds for research among adolescent mothers and their infants in order to increase nursing knowledge in this area.

\section{Implications for Policy}

Adolescent pregnancy is a challenge to most countries of the world. Different countries approach this problem differently depending on cultural beliefs and economy. The findings of this study have important policy implications in a number of areas, including education, economy and health.

\section{Education}

Both groups of unmarried and married adolescent mothers were older and had lower levels of education than the group of their never-pregnant counterparts. These findings support earlier findings indicating that adolescent pregnancy limits educational opportunities (Mturi \& Moerane, 2001:260; William, \& Mavundla T.R., (1999). Policy makers can potentially use the findings of this study to implement programmes that will help adolescents to postpone pregnancy and to continue with their education. Ageappropriate information on sexuality needs to be introduced early in life and continued throughout high school. Adolescents who become pregnant should not be dismissed from school without alternative programmes. Lesotho needs to develop altemative high school programmes so that these adolescents can complete their high school education and potentially lead productive lives.

\section{Economy}

Policy makers in Lesotho need to develop and implement policies that will not only keep adolescents in school to complete their high school education, but also help them become self-reliant through skills development programmes. Adolescent pregnancy not only drains resources from relatives and friends, but also drains the economy of the country as whole. For example, health care is subsidized by the government in Lesotho. Services such as immunization are free. Therefore, early childbearing creates more financial burden on the country.

\section{Health}

Cocky (1997:32) suggests that adolescent pregnancy should be viewed as a public health problem rather than a moral issue. This investigator further indicates that industrialized countries such as the United Kingdom and Japan that have used this approach have managed to reduce adolescent pregnancy. Perhaps Lesotho should follow this approach in order to reduce adolescent pregnancy and its negative impact on the health of adolescents.

\section{Limitations}

Two methodological limitations were identified in this study. Firstly, the sample in this study was a convenience sample from the lowlands in Lesotho. Therefore, the results may not be generalized to the entire population, including adolescents in the mountainous areas. Secondly, this was a cross-sectional study. Variables such as immunization status and nutritional status need to be observed over time in order to contribute more meaningful results. However, despite these methodological problems, this study provides useful information on perceived stress, and health outcomes among adolescent mothers and their infants in Lesotho.

\section{Summary}

Findings of this study indicate that pregnancy and parenting among adolescents have a negative impact on the health of adolescent mothers in the lowlands of Lesotho. Faced with developmental tasks of adolescence, teenage mothers find pregnancy and parenting to be stressful events. Seemingly not having a baby and continuing with the one's education lead to health benefits for these adolescents. Never-pregnant adolescents had better health outcomes than the two groups of unmarried and married adolescent mothers including the lowest levels of stress. Infants of both unmarried and married mothers had similar results in terms of birth weight, nutritional status, and immunization status.

\section{Recommendations}

It is recommended that a larger study, in which the sample includes adolescents from the mountainous areas, be done in order to generalize the findings to the entire population in Lesotho. It is also recommended that longitudinal studies which test nutritional status and immunization status of infants be done. These longitudinal studies will help nurses to identify infants that are at more risk of malnutrition or of not getting all their required immunizations at the appropriate time.

\section{References}

AMINI, SB; CATALANO, PM; DIERKER, LJ \& MANN, LT 1996. Births and teenagers: Trends and obstetric outcomes. Obstetrics and Gynecology, 87 (5): 668-674.

BURNS, N \& GROVE, SK 1993. The practice of nursing research. 2nd edition. Philadelphia: W. B. Saunders Co.

COCKEY, CD 1997. Preventing teen pregnancy: It's time to stop kidding around. AWHONN Lifelines, 1 (3):32-40.

COHEN, J 1988. Statistical power analysis for the behavioral sciences. 2nd edition. Hillsdale, N. J.: L. Erlbaum Associates.

COPYWRITE 2000. Lesotho review. http://www.lesotho.gov.ls/lshealth.htm

DELONGIS, A; FOLKMAN, S \& LAZARUS, RS 1988. The impact of daily stress on health and mood: Psychological and social resources as mediators. Journal of Personality \& Social Psychology, 54 (3): 486-495.

GLAZER, G 1979. Concerns and level of anxiety in pregnant women. Unpublished master's thesis, Case Western Reserve University, Cleveland.

GLAZER, G. 1984. Relationship between pregnancy, woman's anxiety levels and stressors, and their partner's anxiety levels and stressors. Unpublished Doctor of Philosophy dissertation, Case Western Reserve University, Cleveland.

KELLY, LE 1995. Adolescent mothers: What factors relate to level of preventive health care sought for their infant? Journal of Pediatric Nursing, $10(2)$ : 105 113.

LESOTHO PLANNED PARENTHOOD ASSOCIATION 2005. Lesotho country profile. http//ippfnet.ippf.org/pub/IPPFRegions/IPPF-countryProfile.asp

MNGADI, PI; THEMBI, IT; RANSJOARVIDSON, AB \& AHLBERG, BM 
2002. Quality of maternity care for adolescent mothers in Mbabane, Swaziland. Intermational Nursing Review, 49 (1): $38-46$.

MOON, MW; KHUMALOSAKUTUKWA, GN; MBIZVO, MT \& PADIAN, NS 2002. Vaginal microbicides for HIV/STI prevention in Zimbabwe: What key informants say. Transcultural Nursing 13(1):19-23.

MOTLOMELO,ST \& SEBATANE, EM

1999. A study of adolescents health problems in Leribe Maseru and Mafeteng districts of Lesotho. Maseru: Government Printer.

MTURI, AK \& MOERANE, W 2001. Premarital childbearing among adolescents in Lesotho. Journal of Southern African Studies, 27 (2): 259 276).

NAEYE, RL 1981. Teenaged and preteenaged pregnancies: consequences of the fetal-maternal competition for nutrients. Pediatrics, 67 (1): 146-150.

OKPANI, AO \& OKPANI, JU 2000. Sexual activity and contraceptive use among female adolescents: A report from Port Harcourt, Nigeria. African Journal of Reproductive Health 4 ( 1 ): 40-7.

OMOLE, DA 2000. Poverty in Lesotho. WWW. Gdnct.org/fulltext/omole

SELLER, PM 2003. Midwifery. Lansdown: Juta

SELYE, H 1956. The stress of life. New York: McGrow-Hill Book Co.

TOPF, M 1986. Three estimates of interrater reliability for nominal data. Nursing Research, 35 (4):253-2.54.

UNICEF, 2003. Girls' education in Lesotho. www.unicef.org/girlseduction/ index.html

IUNDILE,C; MAFORAH,F; JEWKES, R \& JORDAAN, E 2001.Risk factors for teenage pregnancy among sexually active black adolescents in Cape Town: A case control study. South African Medical Journal 91 (1): 73-80.

WIILIAMS, CX \& MAVUNDLA, TR 1999. Teenage mother' knowledge of sex education in a general hospital of the Umtata district. Curationis, 22 (1): 58-63.
WOOD, K; MAFORAH, F \& JEWKES,

R 1998. He forced me to love him: Putting violence on adolescent sexual health agenda. Social Science and Medicine, $47(2): 233-242$.

WORLDBANK 2004. Lesotho data profïle. http://devdat.worldbank.org/ cpprofile.

WORLD FACTBOOK 2003. Lesotho. WWW.Bartleby.com

YAKO, EM 2000. A comparison of perceived stress, psychological responses to stress, and health outcomes among unmarried and married 15-19-year old adolescent mothers and their infants in Lesotho. Unpublished Doctoral Dissertation. Cleveland (Ohio), Case Western University. 